\title{
Temporal effects of final action on the performance of the Portuguese men's volleyball teams
}

\author{
Ricardo Lima ${ }^{1,2}$, Ana Filipa Silva ${ }^{1,3}$, Filipe Manuel Clemente ${ }^{1,4}$ \\ ${ }^{1}$ Polytechnic of Viana do Castelo - School of Sports and Leisure from Melgaço, Portugal; ${ }^{2}$ Research Center in Sports \\ Sciences, Health Sciences and Human Development - CIDESD, Vila Real, Portugal; ${ }^{3}$ Research Nucleus of Polytechnic \\ Institute of Maia (N2I), Maia, Portugal; ${ }^{4}$ Institute for Telecommunications - Covilhã Department, Portugal
}

\section{Summary}

Study aim: The purpose of this study was twofold: (i) to compare total attacks, points in the defense phase and attack efficiency between playing positions; and (ii) to identify the main predictors of overall volleyball teams' success related to points made during the game.

Material and methods: 282 sets with a total of 33174 actions and 8231 points were analyzed. The study included 14 teams participating in the male First Division Portuguese Championship (53 games from the 2016/2017 season and 27 from the first phase of the 2017/2018 season, for a total of 80 matches).

Results: The most important parameters for the overall performance are efficacy of points in defense phase, aces, block points, and attack efficiency. Overall team performance variables statistically significantly predicted the total points of the team, $F_{16,1091}=39.375, p<0.001, R^{2}=0.366$. Considering the comparisons between players' performances, it was found that the setter had the lowest number of points in the defense phase and total attacks. Opposites had more total attacks and points in the defense phase than the other players (at a small-to-moderate magnitude).

Conclusion: The results revealed the importance of the efficacy of points in the defense phase, namely regarding the service action, block point, and attack efficiency, to improve the possibilities of winning.

Keywords: Game analysis - Performance in volleyball - Playing positions - Volleyball software analysis

\section{Introduction}

Volleyball is one of the most popular in the world. As a dynamic sport, where a technical error can give a point to the opponent, the unpredictability is constant. To achieve strong performances and high ranking positions, the players have to have not only superior anthropometrics, body composition, and somatotype characteristics [24], but also good tactical and technical actions - namely, receptions, services, attacks, blocks, and sets [10]. Of those, attacks, blocks, and serves, due to the possibility of scoring a direct point, are considered scoring skills [19] or terminal actions [28]. By contrast, the defense, setting, and reception procedures are characterized as non-scoring skills [19] or intermediate actions, and thus should, at first glance, not be the main variables to predict success [27].

Studies has been conducted analyzing the technical actions to predict the team's success. The attacking, the serving and blocking actions have been identified as the best indicators of success in high-level volleyball teams $[11,12,16,23,26]$. In fact, a great number of studies indicate the attack as the main action to score, with the opposite hitter (followed by the outside hitter or receivers) as the most requested player to perform the attack [3, 7]. In addition, being the first terminal action, blocking seems to offer a greater chance to win [22]. However, other authors have noted that the service action also plays an important role to achieve results in top level competitions [5, 10, 28]. Indeed, Marcelino et al. [3] found that the teams that win the sets performed on average 1.32 points per set, in contrast to 0.79 of the losing teams.

The non-scoring skills, i.e. those with which teams cannot directly win points, have also been indicated as important for success in competition [14]. In fact, it has been noted that winning points in high-level competitions requires perfect receptions (when the setter can pass the ball to all attackers in a perfect condition) [7, 27]. In this regard, it was also verified that, in the reception, the winning teams make less perfect receptions although they also 
make fewer mistakes, obtaining a more favorable relation between both, resulting in superior values of the coefficient of the performance [19]. Moreover, other studies found as success predictors a combination of scoring and non-scoring skills. For example, Laios et al. [15] revealed that team rankings are strongly dependent on their serving and passing efficacy because the balance between serving and receiving is an important characteristic of a successful team. Also, Monteiro et al. [21] found a significant association between the attack efficacy and the set outcome since the teams that win the sets make fewer errors and have a higher efficacy in the counter-attack.

The determinants of success seem to depend on the team's characteristics, as well as on the playing positions' efficacies. However, there is still a lack of studies comparing the different skills between playing positions. While several articles have revealed various indicators of performance associated with volleyball success, no study has been conducted with male Portuguese teams with a great range of data over more than one season to really understand the predictors of success. Therefore there is a need to understand the patterns in the male Portuguese League, mainly because volleyball in Portugal is growing and international results start to appear with the national team and European competitions by clubs.

Considering the above issues, the aim of this study was to analyze the performance variables of total points, points in the defense phase and attack efficiency, that can predict teams' overall success in volleyball. Moreover, the performance for different playing positions was compared for descript variables above in an attempt to understand each position's contribution to the success/defeat of the team. The novelty of the present study will contribute to understanding the differences between win/defeat as well as differences in technical actions between playing positions. The comparison of the skill actions between playing positions can give interesting results to improve the training sessions.

\section{Material and methods}

\section{Participants}

The study included fourteen teams participating in the male First Division Portuguese Championship. In the 2016/2017 season the game analysis of 12 teams was performed, while in the 2017/2018 season two more teams than the previous season were analyzed, with a total of 1109 volleyball players. We analyzed 53 games from first and second phase of the 2016/2017 season and 27 from the first phase of the 2017/2018 season, with a total of 80 matches. 10 of the total matches had 5 sets played, 22 had 4 sets played and 48 had only 3 sets played. We analyzed 282 sets with a total of 33174 actions (attack, block, service and reception). These 33174 actions resulted in 8231 points scored (not counting the errors from the opponent). To perform the analysis, informed consent was given by the Portuguese Volleyball Federation. The study followed the ethical recommendations of the Declaration of Helsinki for the study of humans.

\section{Design and procedures}

The data for the current study were collected using the statistical programs Data Volley and Click and Scout. Data Volley is a statistical program that is used by top volleyball teams because it can analyze technical and tactical actions by player, by skill, and by rotation [8]. Regarding the Click and Scout statistical software, it is an important tool for analyzing the technical and tactical efficacy of the team and the opponent [2].

In a previous study, it was found that the software allowed users to achieve intra-observer reliability values between 0.96 and 1 and inter-observer reliability values between 0.98 and 1 [28]. Aiming to test the reliability of the data, we used $5 \%$ of the full data using 4 observers with 7 and 14 years of experience in volleyball game analysis for intra - and inter-reliability [25]. The test-retest was made in the first games during the beginning of data collection with a 30 -day interval. The intra-class correlation test (ICC) revealed good values of intra-reliability (0.76) and inter-reliability (0.74) being consistent for use in this type of study. After testing the reliability with our observers, we compared our data with the match reports' data, and no significant differences were found using the Cohen $\mathrm{d}$ test $(\mathrm{d}=0.012$, trivial). Moreover, nearly perfect correlations between our data and the match report data were found using the Pearson test $(r=0.96)$. After such tests, we confirmed that the data coming from match reports were reliable and trustable.

All the matches were obtained from official match reports of the male First Division Portuguese Championship between September 2016 and March 2018 after being observed live by 6 statistician observers. The match reports included technical analyses by player (outside hitter - left side wing spiker; opposite - right side of the net player; setter; middle blocker). In this study the libero was not included in the final analysis and it was only part of the sample of the 6 players who started the different sets in the game, excluding the substitutions during the set. The following variables were analyzed between playing positions: points obtained in the defense phase, total attacks performed by each athlete, attack efficiency (\%) - the attack efficiency value is an index that uses the ratio between winning hits minus the missed ones, divided by the total number of hits (Formula: Attack Efficiency \% = (n Attack Points - n Attack Error)/Total Attacks). Regarding the relationships between points of the team and individualized performance of players, the following variables 
were analyzed: points in defense phase (breaking-points), point-error relationship, service error, aces, reception error, attacks error, blocked attacks, attacking points, attack efficiency and block points.

In accordance with Federation International of Volleyball (FIVB) official rules of the game, the final score converted into points earned by the team $(0,1,2$ or 3$)$ was also considered in the regression analysis ( 0 points $=0: 3$ or $1: 3 ; 1$ point $=2: 3 ; 2$ points $=3: 2 ; 3$ points: $3: 0$ or $3: 1$ ) and descriptive analysis.

\section{Statistical analysis}

Between-playing-positions variations were analyzed using the standardized differences of effect size (ES), with a $90 \%$ confidence interval (CI) [6]. The following scale was used to interpret the magnitude of changes [4]: $<0.2=$ trivial; $0.2-0.6=$ small; $0.6-1.2=$ moderate; and $>1.2$ = large. Probabilities were tested by considering the smallest worthwhile changes ( $\mathrm{SW}, 0.2 \mathrm{x}$ between-subjects SD) [13]. The following scale for qualitative probabilities was used [10]: 25-75\% = possibly; 75-95\% = likely; $95-99 \%=$ very likely; and $>99 \%=$ almost certain. The computation of statistical procedures was made in a specific spreadsheet, as per Hopkins.

A multiple regression analysis was used to predict total points and final score (points earned at the end of the match) based on the values of individualized performance variables. Multiple regression was calculated based on the Bland-Altman plot that considers the average between the expected and obtained scores on the $\mathrm{x}$-axis and differences between the obtained and expected scores on the y-axis. Collinearity statistics were tested before the final model. A threshold of 2.5 for the variance inflation factor was defined to exclude variables and to avoid multicollinearity. The level of significance was established as $\alpha=0.05$. The statistical procedures were performed using SPSS software (version 23.0, IBM, USA).

\section{Results}

\section{Between playing position changes}

Descriptive statistics of points in the defense phase, total attacks and attack efficiency made by different playing positions in the games that finished with $0,1,2$ or 3 points $(0$ points $=0: 3$ or $1: 3 ; 1$ point $=2: 3 ; 2$ points $=3: 2$; 3 points: $3: 0$ or $3: 1$ ) can be observed in Table 1 .

Table 2 shows the percentage of difference between playing positions for total attacks and the standardized differences. Opposites had almost certain large increases of total attacks when compared with setters in 0 points (ES (effect size): 2.76), 1 point (ES: 1.64), 2 points (ES: 3.81) and 3 points (ES: 3.59 ). Middle blockers had almost certain large decreases of total attacks when compared with

Table 1. Descriptive statistics $(\mathrm{M} \pm \mathrm{SD})$ of the points in defense phase, total attacks and attack efficiency by playing position in the final scores of $0,1,2$ or 3 points

\begin{tabular}{|c|c|c|c|c|}
\hline & Setter $M \pm S D$ & Opposite $\mathrm{M} \pm \mathrm{SD}$ & Middle Blocker $\mathrm{M} \pm \mathrm{SD}$ & Outside Hitter $\mathrm{M} \pm \mathrm{SD}$ \\
\hline \multicolumn{5}{|l|}{0 points } \\
\hline Points in defense phase [n] & $0.84 \pm 1.02$ & $2.77 \pm 2.56$ & $1.14 \pm 1.11$ & $1.88 \pm 1.78$ \\
\hline Total Attacks [n] & $2.59 \pm 3.86$ & $23.02 \pm 11.15$ & $7.32 \pm 4.58$ & $14.23 \pm 8.11$ \\
\hline Attack efficiency [\%] & $35.84 \pm 35.90$ & $36.63 \pm 13.23$ & $41.91 \pm 24.21$ & $37.98 \pm 20.31$ \\
\hline \multicolumn{5}{|l|}{1 point } \\
\hline Points in defense phase [n] & $2.38 \pm 1.71$ & $6.50 \pm 3.61$ & $3.52 \pm 2.00$ & $3.59 \pm 2.26$ \\
\hline Total Attacks [n] & $3.08 \pm 3.07$ & $37.67 \pm 18.22$ & $11.39 \pm 5.84$ & $20.22 \pm 11.15$ \\
\hline Attack efficiency [\%] & $27.31 \pm 32.29$ & $47.33 \pm 14.26$ & $47.96 \pm 23.94$ & $43.74 \pm 10.72$ \\
\hline \multicolumn{5}{|l|}{2 points } \\
\hline Points in defense phase $[\mathrm{n}]$ & $1.60 \pm 1.76$ & $5.29 \pm 3.50$ & $3.96 \pm 2.40$ & $4.27 \pm 2.46$ \\
\hline Total Attacks [n] & $2.47 \pm 2.33$ & $29.07 \pm 17.13$ & $11.00 \pm 4.82$ & $21.38 \pm 8.17$ \\
\hline Attack efficiency [\%] & $25.20 \pm 32.88$ & $43.71 \pm 16.42$ & $57.54 \pm 16.21$ & $44.23 \pm 12.88$ \\
\hline \multicolumn{5}{|l|}{3 points } \\
\hline Points in defense phase [n] & $1.51 \pm 1.37$ & $4.59 \pm 2.66$ & $3.27 \pm 1.94$ & $4.11 \pm 2.31$ \\
\hline Total Attacks [n] & $1.64 \pm 1.72$ & $29.76 \pm 9.16$ & $8.18 \pm 4.17$ & $15.28 \pm 9.03$ \\
\hline Attack efficiency [\%] & $35.50 \pm 41.44$ & $49.86 \pm 13.53$ & $61.68 \pm 22.24$ & $50.66 \pm 17.00$ \\
\hline
\end{tabular}


Table 2. Total attacks comparison between playing positions

\begin{tabular}{|c|c|c|c|}
\hline (A vs. B) & $\begin{array}{c}\% \text { difference }(90 \% \mathrm{CI}) \\
\text { (A vs. B) }\end{array}$ & $\begin{array}{c}\% \text { greater/similar/lower } \\
\text { (A vs. B) }\end{array}$ & $\begin{array}{l}\text { ES and magnitude } \\
\text { inference (A vs. B) }\end{array}$ \\
\hline \multicolumn{4}{|l|}{0 points } \\
\hline Opposite vs. Setter & $729.7[582.2 ; 904.7]$ & 100/0/0 Almost certain & 2.76 large \\
\hline Middle Blocker vs. Setter & $144.2[101.8 ; 195.6]$ & 100/0/0 Almost certain & 1.16 moderate \\
\hline Outside Hitter vs. Setter & $377.6[294.9 ; 477.7]$ & 100/0/0 Almost certain & 2.04 large \\
\hline Middle Blocker vs. Opposite & $-70.6[-74.3 ;-66.3]$ & 0/0/100 Almost certain & -2.33 large \\
\hline Outside Hitter vs. Opposite & $-42.4[-49.7 ;-34.2]$ & 0/0/100 Almost certain & -1.05 moderate \\
\hline Outside Hitter vs. Middle Blocker & $95.6[71.2 ; 123.5]$ & 100/0/0 Almost certain & 0.95 moderate \\
\hline \multicolumn{4}{|l|}{1 point } \\
\hline Opposite vs. Setter & $932.3[497.3 ; 1684.1]$ & 100/0/0 Almost certain & 3.32 large \\
\hline Middle Blocker vs. Setter & $229.0[117.2 ; 398.4]$ & 100/0/0 Almost certain & 1.69 large \\
\hline Outside Hitter vs. Setter & $465.7[275.1 ; 753.1]$ & 100/0/0 Almost certain & 2.47 large \\
\hline Middle Blocker vs. Opposite & $-68.1[-80.6 ;-47.6]$ & 0/0/100 Almost certain & -1.23 large \\
\hline Outside Hitter vs. Opposite & $-45.2[-66.6 ;-10.1]$ & 1/7/92 Likely & -0.65 moderate \\
\hline Outside Hitter vs. Middle Blocker & $71.9[23.8 ; 138.7]$ & 98/2/0 Very likely & 0.78 moderate \\
\hline \multicolumn{4}{|l|}{2 points } \\
\hline Opposite vs. Setter & $822.1[518.7 ; 1274.4]$ & 100/0/0 Almost certain & 3.81 large \\
\hline Middle Blocker vs. Setter & $219.9[121.7 ; 361.7]$ & 100/0/0 Almost certain & 1.99 large \\
\hline Outside Hitter vs. Setter & $553.6[366.3 ; 816.1]$ & 100/0/0 Almost certain & 3.22 large \\
\hline Middle Blocker vs. Opposite & $-65.3[-76.0 ;-49.8]$ & 0/0/100 Almost certain & -1.66 large \\
\hline Outside Hitter vs. Opposite & $-29.1[-49.5 ;-0.5]$ & 1/13/86 Likely & -0.54 small \\
\hline Outside Hitter vs. Middle Blocker & $104.3[51.7 ; 175.1]$ & 100/0/0 Almost certain & 1.01 moderate \\
\hline \multicolumn{4}{|l|}{3 points } \\
\hline Opposite vs. Setter & $835.5[690.5 ; 1007.1]$ & 100/0/0 Almost certain & 3.59 large \\
\hline Middle Blocker vs. Setter & $258.5[205.7 ; 320.4]$ & 100/0/0 Almost certain & 2.05 large \\
\hline Outside Hitter vs. Setter & $571.6[473.2 ; 686.9]$ & 100/0/0 Almost certain & 3.06 large \\
\hline Middle Blocker vs. Opposite & $-61.7[-66.2 ;-56.6]$ & 0/0/100 Almost certain & -1.76 large \\
\hline Outside Hitter vs. Opposite & $-28.2[-36.6 ;-18.7]$ & 0/0/100 Almost certain & -0.61 moderate \\
\hline Outside Hitter vs. Middle Blocker & $87.3[67.6 ; 109.4]$ & 100/0/0 Almost certain & 1.04 moderate \\
\hline
\end{tabular}

ES: effect size measured as standardized differences of Cohen (d). The value of Cohen, \% of difference and probabilities represents the difference of A-B, thus if positive means that $\mathrm{A}$ had greater results than B and if negative values means that B had more than A. The \%greater/similar/lower represents the probabilities tested by considering the smallest worthwhile changes (detailed information can be observed on the statistical procedures section). Legend: ( 0 points $=0: 3$ or $1: 3 ; 1$ point $=2: 3 ; 2$ points $=3: 2 ; 3$ points: $3: 0$ or $3: 1)$.

opposites in 0 points (ES: -2.33$)$, 1 point (ES: -1.23$)$, 2 points [ES: -1.66$)$ and 3 points (ES: -1.76$)$.

Table 3 shows the percentage of difference between playing positions for points in the defense phase. In the 1 point earned scenario, almost certain large decreases of points in the defense phase were found in outside hitter in comparison to opposites (ES: -1.25 ). In the 3 points scenario, outside hitters had almost certain large increases of points in the defense phase in comparison to setters (ES: 1.30). Also, in the 3 points scenario, opposites had almost certain large increases of points in the defense phase when compared with setters (ES: 1.53).

Table 4 shows the percentage of difference between playing positions for attack efficiency. Only trivial-tomoderate variations were found in the comparisons made by playing positions for the variable attack efficiency. 
Table 3. Points in defense phase comparison between playing positions

\begin{tabular}{|c|c|c|c|}
\hline (A vs. B) & $\begin{array}{c}\% \text { difference }(90 \% \mathrm{CI}) \\
\text { (A vs. B) }\end{array}$ & $\begin{array}{c}\% \text { greater/similar/lower } \\
(\text { A vs. B) }\end{array}$ & $\begin{array}{c}\text { ES and magnitude infer- } \\
\text { ence (A vs. B) }\end{array}$ \\
\hline \multicolumn{4}{|l|}{0 points } \\
\hline Opposite vs. Setter & $78[47.7 ; 114.5]$ & 100/0/0 Almost certain & 1.22 large \\
\hline Middle Blocker vs. Setter & $-1.7[-15.0 ; 13.7]$ & 10/71/19 Unclear & -0.04 trivial \\
\hline Outside Hitter vs. Setter & $53.4[31.9 ; 78.3]$ & 100/0/0 Almost certain & 0.91 moderate \\
\hline Middle Blocker vs. Opposite & $-44.8[-53.0 ;-35.0]$ & 0/0/100 Almost Certain & -0.84 moderate \\
\hline Outside Hitter vs. Opposite & $-13.8[-27.1 ; 1.8]$ & 0/47/53 Possibly & -0.21 small \\
\hline Outside Hitter vs. Middle Blocker & $56.0[38.6 ; 75.6]$ & 100/0/0 Almost certain & 0.91 moderate \\
\hline \multicolumn{4}{|l|}{1 point } \\
\hline Opposite vs. Setter & $233.7[117.4 ; 412.2]$ & 100/0/0 Almost certain & 1.64 large \\
\hline Middle Blocker vs. Setter & $79.0[21.3 ; 164.2]$ & $97 / 3 / 0$ Very likely & 0.79 moderate \\
\hline Outside Hitter vs. Setter & $62.7[9.6 ; 141.5]$ & 92/7/1 Likely & 0.66 moderate \\
\hline Middle Blocker vs. Opposite & $-46.4[-62.0 ;-24.3]$ & 0/1/99 Very likely & -1.09 moderate \\
\hline Outside Hitter vs. Opposite & $-51.2[-65.7 ;-30.7]$ & 0/0/100 Almost Certain & -1.25 large \\
\hline Outside Hitter vs. Middle Blocker & $-9.1[-32.4 ; 22.2]$ & 12/42/46 Unclear & -0.17 trivial \\
\hline \multicolumn{4}{|l|}{2 points } \\
\hline Opposite vs. Setter & $78.4[16.7 ; 172.6]$ & $96 / 3 / 1$ Very likely & 1.02 moderate \\
\hline Middle Blocker vs. Setter & $33.8[-10.0 ; 98.9]$ & 78/18/5 Likely & 0.51 small \\
\hline Outside Hitter vs. Setter & $37.2[-6.9 ; 102.2]$ & 81/15/4 Likely & 0.55 small \\
\hline Middle Blocker vs. Opposite & $-25.0[-48.1 ; 8.3]$ & 3/20/77 Likely & -0.46 small \\
\hline Outside Hitter vs. Opposite & $-23.1[-46.2 ; 9.9]$ & 4/22/74 Possibly & -0.42 small \\
\hline Outside Hitter vs. Middle Blocker & $2.5[-25.6 ; 41.4]$ & 28/52/20 Unclear & 0.04 trivial \\
\hline \multicolumn{4}{|l|}{3 points } \\
\hline Opposite vs. Setter & $133.5[99.5 ; 173.2]$ & 100/0/0 Almost certain & 1.53 large \\
\hline Middle Blocker vs. Setter & $71.8[49.2 ; 97.9]$ & 100/0/0 Almost certain & 0.98 moderate \\
\hline Outside Hitter vs. Setter & $105.8[78.0 ; 138.0]$ & 100/0/0 Almost certain & 1.30 large \\
\hline Middle Blocker vs. Opposite & $-26.4[-35.3 ;-16.2]$ & 0/1/99 Very likely & -0.53 small \\
\hline Outside Hitter vs. Opposite & $-11.8[-22.9 ; 0.8]$ & 0/44/56 Possibly & -0.22 small \\
\hline Outside Hitter vs. Middle Blocker & $19.8[6.9 ; 34.3]$ & 83/17/0 Likely & 0.32 small \\
\hline
\end{tabular}

ES: effect size measured as standardized differences of Cohen (d). The value of Cohen, $\%$ of difference and probabilities represents the difference of A-B, thus if positive means that A had greater results than B and if negative values means that B had more than A. The \%greater/similar/lower represents the probabilities tested by considering the smallest worthwhile changes (detailed information can be observed on the statistical procedures section). Legend: ( 0 points $=0: 3$ or $1: 3 ; 1$ point $=2: 3 ; 2$ points $=3: 2 ; 3$ points: $3: 0$ or $3: 1$ ).

\section{Relationships between points of the team and individualized performance of players}

A multiple regression analysis was run to predict total points of the teams from total points by player, points in the defense phase (breaking points), point-error relationship, total serves, service error, aces, total receptions, reception error, positive reception, perfect reception, total attacks, attacks error, blocked attacks, attacking points, attack efficiency and block points.

These variables statistically significantly predicted total points of the team, $F_{16,1091}=39.375, p<0.001, R^{2}=0.366$. The variables of transition points $(p=0.001)$, point-error relationship $(p=0.040)$, total serves $(p=0.001)$, positive reception $(p=0.047)$, perfect reception $(p=0.005)$, total 
Table 4. Attack efficiency comparison between playing positions

\begin{tabular}{|c|c|c|c|}
\hline (A vs. B) & $\begin{array}{c}\% \text { difference }(90 \% \mathrm{CI}) \\
\text { (A vs. B) }\end{array}$ & $\begin{array}{c}\% \text { greater/similar/lower } \\
\text { (A vs. B) }\end{array}$ & $\begin{array}{c}\text { ES and magnitude inference } \\
\text { (A vs. B) }\end{array}$ \\
\hline \multicolumn{4}{|l|}{0 points } \\
\hline Opposite vs. Setter & $-39.1[-46.4 ;-30.7]$ & 0/0/100 Almost certain & -1.15 moderate \\
\hline Middle Blocker vs. Setter & $-23.7[-32.5 ;-13.8]$ & 0/1/99 Very likely & -0.63 moderate \\
\hline Outside Hitter vs. Setter & $-34.7[-42.1 ;-26.4]$ & 0/0/100 Almost certain & -0.99 moderate \\
\hline Middle Blocker vs. Opposite & $25.2[13.3 ; 38.4]$ & 99/1/0 Very likely & 0.54 small \\
\hline Outside Hitter vs. Opposite & $7.1[-2.7 ; 18.0]$ & 41/59/0 Possibly & 0.17 trivial \\
\hline Outside Hitter vs. Middle Blocker & $-14.4[-21.6 ;-6.5]$ & 0/12/88 Likely & -0.34 small \\
\hline \multicolumn{4}{|l|}{1 point } \\
\hline Opposite vs. Setter & $0.6[-32.8 ; 50.7]$ & 31/41/29 Unclear & 0.01 trivial \\
\hline Middle Blocker vs. Setter & $8.5[-27.5 ; 62.4]$ & 43/38/19 Unclear & 0.14 trivial \\
\hline Outside Hitter vs. Setter & $-7.2[-37.6 ; 37.9]$ & 19/39/42 Unclear & -0.12 trivial \\
\hline Middle Blocker vs. Opposite & $7.8[-12.7 ; 33.2]$ & $53 / 34 / 13$ Unclear & 0.23 small \\
\hline Outside Hitter vs. Opposite & $-7.8[-23.7 ; 11.4]$ & 10/35/56 Unclear & -0.25 small \\
\hline Outside Hitter vs. Middle Blocker & $-14.5[-29.0 ; 2.9]$ & 2/24/74 Possibly & -0.37 small \\
\hline \multicolumn{4}{|l|}{2 points } \\
\hline Opposite vs. Setter & $-5.0[-35.8 ; 40.5]$ & 22/41/38 Unclear & -0.09 trivial \\
\hline Middle Blocker vs. Setter & $14.4[-22.5 ; 68.8]$ & $53 / 34 / 13$ Unclear & 0.23 small \\
\hline Outside Hitter vs. Setter & $-12.9[-41.2 ; 29.0]$ & 13/34/53 Unclear & -0.23 small \\
\hline Middle Blocker vs. Opposite & $20.5[3.8 ; 39.8]$ & 93/6/1 Likely & 0.75 moderate \\
\hline Outside Hitter vs. Opposite & $-8.3[-21.5 ; 7.2]$ & 7/27/65 Unclear & -0.35 small \\
\hline Outside Hitter vs. Middle Blocker & $-23.9[-34.4 ;-11.6]$ & 0/1/99 Very likely & -0.90 moderate \\
\hline \multicolumn{4}{|l|}{3 points } \\
\hline Opposite vs. Setter & $-23.1[-33.6 ;-11.0]$ & 0/4/96 Very likely & -0.50 small \\
\hline Middle Blocker vs. Setter & $-7,6[-20.4 ; 7.2]$ & 2/60/38 Possibly & -0.15 trivial \\
\hline Outside Hitter vs. Setter & $-24.3[-34.6 ;-12.4]$ & 0/3/97 Very likely & -0.53 moderate \\
\hline Middle Blocker vs. Opposite & $20.2[11.5 ; 29.6]$ & 100/0/0 Almost certain & 0.65 moderate \\
\hline Outside Hitter vs. Opposite & $-1.5[-8.3 ; 5.7]$ & 5/78/17 Likely & -0.06 trivial \\
\hline Outside Hitter vs. Middle Blocker & $-18.1[-24.0 ;-11.7]$ & 0/1/99 Very likely & -0.47 small \\
\hline
\end{tabular}

ES: effect size measured as standardized differences of Cohen (d). The value of Cohen, \% of difference and probabilities represents the difference of A-B, thus if positive means that A had greater results than B and if negative values means that B had more than A. The \%greater/similar/lower represents the probabilities tested by considering the smallest worthwhile changes (detailed information can be observed on the statistical procedures section). Legend: ( 0 points $=0: 3$ or $1: 3 ; 1$ point $=2: 3 ; 2$ points $=3: 2 ; 3$ points: $3: 0$ or $3: 1)$.

attacks $(p=0.007)$, blocked attacks $(p=0.008)$, attacking points $(p=0.016)$ and block points $(p=0.040)$ added statistically significantly to the prediction. The unstandardized coefficient $B$ for these variables can be observed in the following Figure 1.

A multiple regression analysis was also run to predict the number of points earned by the team after the end of the game using the same variables of prediction.
These variables statistically significantly predicted points earned by the team, $F_{16,1091}=25.738, p<0.001$, $R^{2}=0.274$. The variables transition points $(p=0.001)$, total serves $(p=0.001)$, aces $(p=0.001)$, blocked attacks $(p=0.001)$ and attack efficiency $(p=0.044)$ added statistically significantly to the prediction. The unstandardized coefficient $B$ for these variables can be observed in the following Figure 2. 

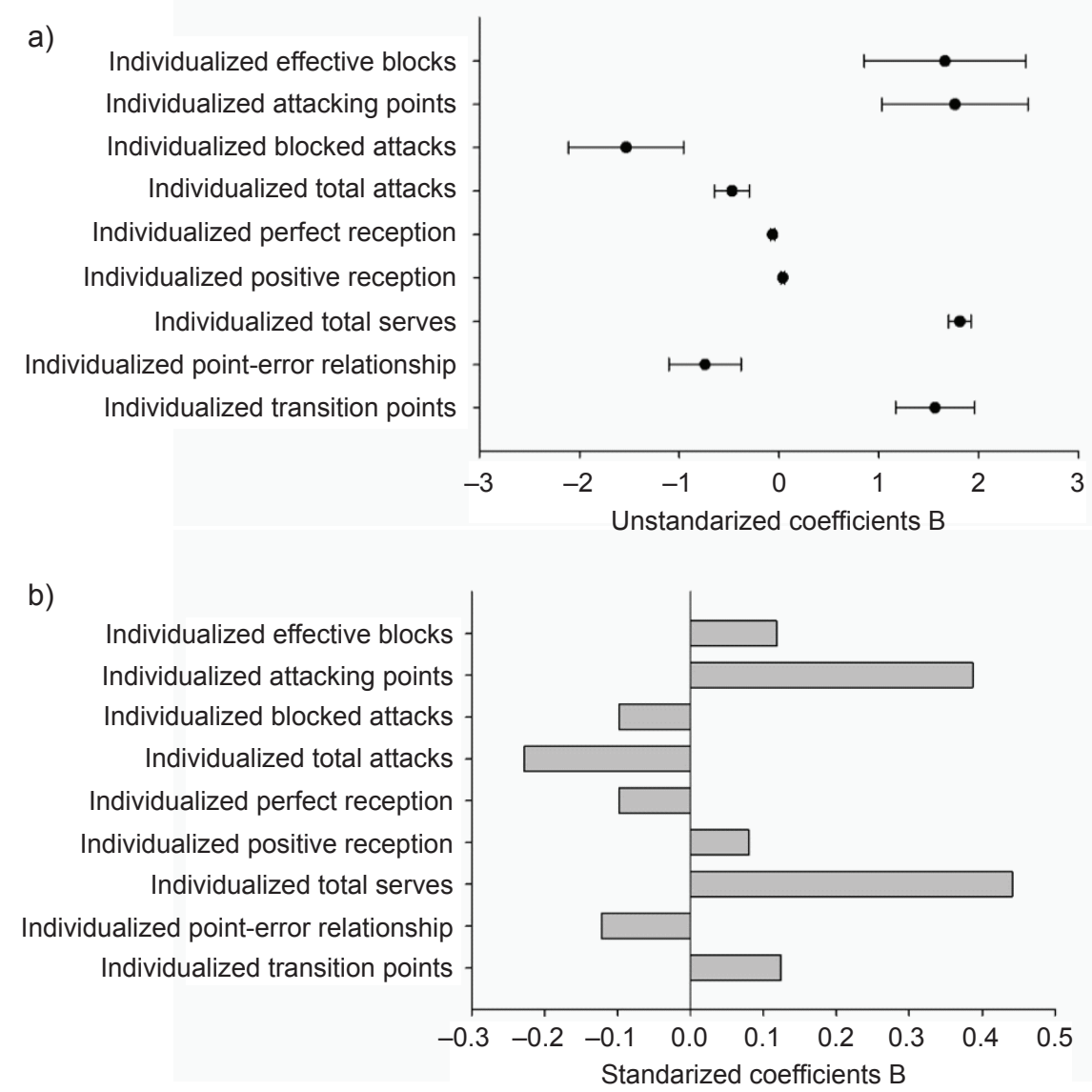

Fig. 1. Unstandardized (a) and standardized (b) coefficient B of individualized variables to predict total points of the teams

\section{Discussion}

The purpose of this study was to analyze the performance variables of total points, points in the defense phase and attack efficiency, that can predict teams' overall success in volleyball as well as compare these variables between playing positions.

The main findings of this study revealed that the most determinant variables contributing to winning games are efficacy of points in defense phase, aces, block points, and attack efficiency. Moreover, it was found that opposite positions are the ones with the greatest volume of total attacks and points in the defense phase and that the setter is more effective than the other positions during attacks.

Thus, it is also important to know that the most important points are played at the end of sets. Besides the fact that volleyball matches present different profiles depending on the match period [15], the results showed that the points in the defense phase, point-error relationship, total serves, positive and perfect receptions, total attacks, attacks blocked, blocked points, and attacking points are the technical actions that predict the success of the team.

These findings agree with previous studies found in the literature, highlighting the importance of technical actions as winning predictors. For example, a study that analyzed performance indicators regarding the result during the set revealed that attack efficiency, block point and service point are the skills which are the most highly correlated with victory [18]. The same results corroborating this research were obtained in a study by Zetou et al. [32] on the effectiveness of skills in men's Olympic volleyball games. Positive and perfect receptions and attack points are the skills that best predict victory.

In the same way, to understand and determine which skills and factors best predict the outcomes of volleyball matches, Pena, Rodriguez-Guerra, Busca, and Serra [23] and Silva, Lacerda, and João [27] revealed that points obtained in the break point phase, service aces, number of reception errors, and blocked attacks were significant predictors of winning or losing. Furthermore, Valhondo, Fernández-Echeverría, González-Silva, Claver, and Moreno [31] studied the serve and reception efficacies of high-level men's volleyball teams. The results showed that the serving player must serve the ball along a descending path at a high speed. Thus, according to Afonso et al. [1], serve-reception practice should preferably cover the deep tennis jump serve, and attempt to afford the libero (because of the specific nature of his position) more opportunities to receive. 

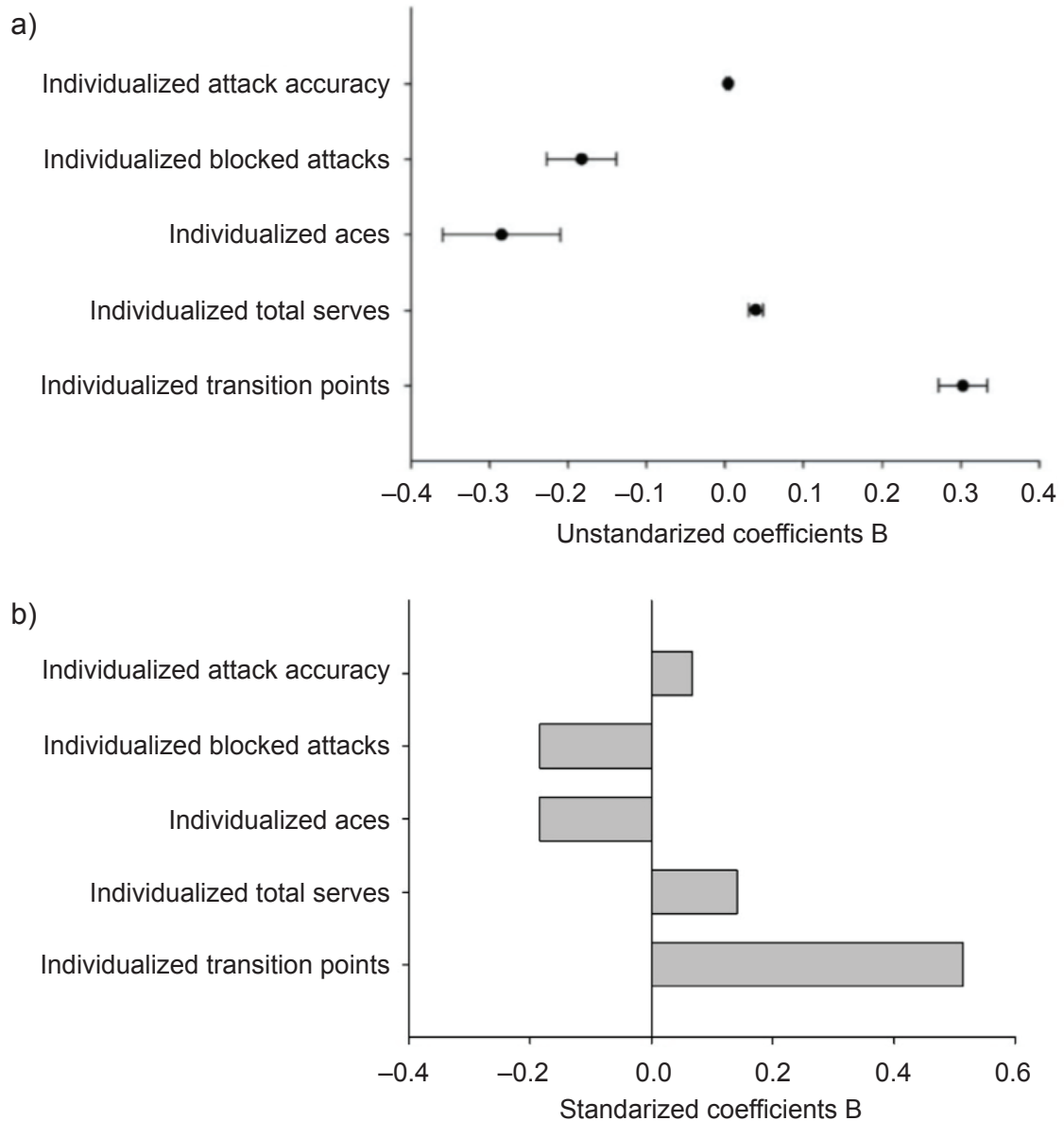

Fig. 2. Unstandardized (a) and standardized (b) coefficient B of individualized variables to predict points earned by the team in the end of the match

Regarding the relationship between the points earned in a game by the team and the individualized performances of players, the variables which significantly predict team performance are the transition points, total of services, aces, blocked attacks, and attack efficiency.

Corroborating this study, Stutzig, Zimmermann, Büsch, and Siebert [30] found that the best predictors of a team's results and team levels are breaking points, attack efficiency, action sequences of defending, setting, and counter-attacking. Furthermore, the tactical position of the setter (offensive zone or defensive zone) and game location (home, away) can also predict winning or losing a game [17, 27].

The setter is the "thinker" in a volleyball game, and the actions and decisions made by this specific player influence the performance of the entire team. Besides that, block tactics and team strategies are characteristics that can also predict and influence the success in the game [3].

Considering the comparison between players' performances, as self-evident, it was found that the setters had the lowest values for breaking points and total attacks. However, they had moderately greater values for efficacy than the other playing positions in lost games. When in the top ranked teams, setters were slightly more effective than all other playing positions, while opposites had more total attacks and breaking points than the other players at a smallto-moderate magnitude.

These results may be caused by the power attack, which is a predictor of complex II attack efficacy [5]. Naturally, because setters are the strategists of the game, they have fewer opportunities to hit the ball, making it more difficult for them to be efficient in attacks. Conversely, opposites are the most common hitters because they attack in both the frontcourt and in the backcourt (second line) [3]. Furthermore, with the technical and tactical evolution, a recent study revealed that the outside hitters present a higher probability of success in their attacks when compared with the opposite player [20]. Hence, increasing the outside hitters from the back court may justify the trivial differences between these two players' positions related to the attack actions.

This study had some limitations. The intra-observer test was only executed in Data Volley. However, the results with click and scout are trustable based on empiric data and the fact that the same observer coded the data, minimizing the lack of reliability. As a suggestion for further 
studies, because of a lack of research in female Portuguese volleyball and differences between genres, it will be interesting to compare the performance analysis of the terminal actions in different competitions and different sexes.

\section{Conclusion}

The results of this study revealed that the most determinant variables contributing to winning games are efficacy of points in the defense phase, aces, block points, and attack efficiency. Moreover, it was found that opposite positions are the ones with the greatest volume of total attacks and points in the defense phase and that the setter is more effective than the other positions during attacks.

Is recommended that coaches include constraints on the tasks proposed during the practices because they are considered an essential part of tactical strategies. Because of this (and to increase players' performance in volleyball) coaches should design exercises that involve tactical conditioning [9].

Hence, in terms of practical applications, the coaches should organize tasks to improve the efficacy of points in the defense phase, service action, individual block, and attack efficiency privileging complex II exercises during the practice. Moreover, coaches must be aware of the importance of guaranteeing that opposites have a high level of efficacy in order to ensure the team's success in matches and to increase the overall efficacy of the team during the attacking process. A mixed approach, based on training processes and data analyses of efficiency processes during matches, may also result in the better performance of the team, increasing its chances of winning.

Conflict of interest: Authors state no conflict of interest.

\section{References}

1. Afonso J., Esteves F., Araújo R., Thomas L., Mesquita I. (2012) Tactical determinants of setting zone in elite men's Volleyball. J. Sports Sci. Med., 11: 64-70.

2. Alexandru S.D., Sabin S.I. (2015) Study on the Interpretation of the Results in a Volleyball Game by Using a Specific Program of Statistics. Procedia - Soc. Behav. Sci., 180: 1357-1363. DOI: 10.1016/j.sbspro.2015.02.277.

3. Araújo R.M., Castro J., Marcelino R., Mesquita I.R. (2010) Relationship between the Opponent Block and the Hitter in Elite Male Volleyball. J. Quant. Anal. Sport, 6. DOI: 10.2202/1559-0410.1216.

4. Batterham A.M., Hopkins W.G. (2006) Making Meaningful Inferences about Magnitudes. Int. J. Sports Physiol. Perform., 1: 50-57. DOI: 10.1123/ijspp.1.1.50.
5. Castro J., Souza A., Mesquita I. (2011) Attack Efficacy in Volleyball: Elite Male Teams. Percept. Mot. Skills, 113: 395-408. DOI: 10.2466/05.25.PMS.113.5.395-408.

6. Cohen J. (1988) Statistical power analysis for the behavioral sciences, $2^{\text {nd }}$ Edition.

7. Costa G., Castro H., Evangelista B., Malheiros L., Greco P., Ugrinowitsch H. (2017) Predicting Factors of Zone 4 Attack in Volleyball. Percept. Mot. Skills, 124: 621-633. DOI: 10.1177/0031512517697070.

8. Data Project (2014) The statistics and analysis software used by the best teams worldwide. http://www.dataproject.com/US/en/Volleyball.

9. Djamel M., Mohamed S. (2015) Level of decision making in some volleyball skills for secondary stage students. Swedish J. Sci. Res., 2: 23-29.

10. Drikos S, Kountouris P, Laios A, Laios Y (2009) Correlates of Team Performance in Volleyball. Int. J. Perform. Anal. Sport, 9: 149-156.

11. Durkovic T., Marelic N., Resetar T. (2008) Influence of the position of players in rotation on differences between winning and loosing teams in volleyball. Int. J. Perform. Anal. Sport, 8: 8-15.

12. Eom H.J., Schutz R.W. (1992) Statistical analyses of volleyball team performance. Res. Q. Exerc. Sport, 63: 11-18. DOI: 10.1080/02701367.1992.10607551.

13. Hopkins W., Marshall S., Batterham A., Hanin J. (2009) Progressive statistics for studies in sports medicine and exercise science. Med. Sci. Sport Exerc., 41: 3.

14. Klaričić I., Grgantov Z., Jelaska I. (2018) Prediction of efficiency in elite volleyball: multiple regression approach. Acta Kinesiol., 12: 79-85.

15. Laios A., Kountouris P. (2017) Receiving and serving team efficiency in Volleyball in relation to team rotation. Int. J. Perform. Anal. Sport, 11: 553-561.

16. Marcelino R., Mesquita I., Afonso J. (2008) The weight of terminal actions in Volleyball. Contributions of the spike, serve and block for the teams' rankings in the World League 2005. Int. J. Perform. Anal. Sport, 8: 1-7. DOI: 10.1080/24748668.2008.11868430.

17. Marcelino R., Mesquita I., Palao J.M., Sampaio J. (2009) Home advantage in high-level volleyball varies according to set number. J. Sport Sci. Med., 8: 352-356.

18. Marcelino R., Mesquita I., Sampaio J. (2011) Effects of quality of opposition and match status on technical and tactical performances in elite volleyball. J. Sports Sci., 29: 733-741. DOI: 10.1080/02640414.2011.552516.

19. Marcelino R., Mesquita I., Sampaio J., Moraes J. (2010) Study of performance indicators in male volleyball according to the set results. Rev. Bras. Educ. Física e Esporte, 24: 69-78.

20. Millán-Sánchez A., Morante Rábago J.C., Ureña Espa A. (2017) Differences in the success of the attack between outside and opposite hitters in high level men's volley- 
ball. J. Hum. Sport Exerc., 12: 251-257. DOI: 10.14198/ jhse.2017.122.01.

21. Monteiro R., Mesquita I., Marcelino R. (2009) Relationship between the set outcome and the dig and attack efficacy in elite male volleyball game. Int. J. Perform. Anal. Sport, 9: 294-305.

22. Palao J.M., Santos J.A., Ureña A. (2004) Effect of team level on skill performance in volleyball. Int. J. Perform. Anal. Sport, 4: 50-60.

23. Pena J., Rodriguez-Guerra J., Busca B., Serra N. (2013) Which skills and factors better predict winning and losing in high-level men's volleyball? J. Strength Cond. Res., 27: 2487-2493.

24. Petroski E.L., Fidelix Y.L., Augusto D., Silva S., Rocha M.A., Oncken P., Viera F.S. (2013) Anthropometric, morpholgical and somatotype characteristics of athletes of the Brazilian Men's Volleyball team: an 11-year descriptive study. Brazilian J. Kinanthropometry Hum. Perform., 184-193.

25. Robinson G., O’Donoghue P. (2007) A weighted kappa statistic for reliability testing in performance analysis of sport. International. J. Perform. Anal. Sport, 7: 12-19.

26. Rodriguez-Ruiz D., Quiroga M., Miralles J., Sarmiento S., Saá Y., Garcia-Manso J. (2011). Study of the technical and tactical variables determining set win or loss in top-level European men's volleyball. Int. J. Perform. Anal. Sport, 7: 1-13.

27. Silva M., Lacerda D., João P. (2013) Match analysis of discrimination skills according to the setter attack zone position in high level volleyball. Int. J. Perform. Anal. Sport, 13: 367-379.

28. Silva M., Lacerda D., João P.V. (2014) Game-related volleyball skills that influence victory. J. Hum. Kinet., 41: 173-179. DOI: 10.2478/hukin-2014-0045.

29. Silva M., Marcelino R., Lacerda D., João P.V. (2016) Match Analysis in Volleyball : a systematic review. Int. J. Perform. Anal. Sport, 5: 35-46.

30. Stutzig N., Zimmermann B., Büsch D., Siebert T. (2017) Analysis of game variables to predict scoring and performance levels in elite men's volleyball Analysis of game variables to predict scoring and performance levels in elite men's volleyball. Int. J. Perform. Anal. Sport, 15: 816-829. DOI: 10.1080/24748668.2015.11868833.

31. Valhondo Á., Fernández-Echeverría C., González-silva J., Claver F., Moreno M.P. (2018) Variables that predict serve efficacy in elite men's volleyball with different quality of opposition sets. J. Hum. Kinet., 61: 167-177. DOI: 10.1515/hukin-2017-0119.

32. Zetou E., Moustakidis A., Tsigilis N., Komninakidou A. (2007) Does Effectiveness of Skill in Complex I Predict Win in Men's Olympic Volleyball Games? J. Quant. Anal. Sport, 3. DOI: 10.2202/1559-0410.1076.

\section{Received 22.03.2019 \\ Accepted 14.08.2019}

(C) University of Physical Education, Warsaw, Poland 